\title{
La coronación de Nuestra Señora de Fernán Ruiz de Sevilla (ID oII6): variantes y variaciones
}

\author{
Natalia Anaís Mangas Navarro \\ Biblioteca Nacional de España \\ nataliamangas 4@hotmail.com \\ https://orcid.org/OoOO-OOO3-I505-75I2
}

Received: 25/05/202I; accepted IO/O7/202I

DOI: https://doi.org/10.7203/MCLM.8.20960

La coronación de Nuestra Señora by Fernán Ruiz de Sevilla (ID oII6): variants and variations

Abstract

A study and cataloguing of Fernán Ruiz de Sevilla’s La coronación de Nuestra Señora (ID oiı6, I5th century). Its two witnesses (ms PN6 and incunabulum Cancionero de Ramón de Llavia, 86* RL) offer abundant divergences. This study helps to shed light on the process of transmission of this poem and suggests hypotheses regarding the affiliation of its sources.

KEYWORDS

Fernán Ruiz de Sevilla; Cancionero de Llavia; variants; incunabula printing; manuscript tradition

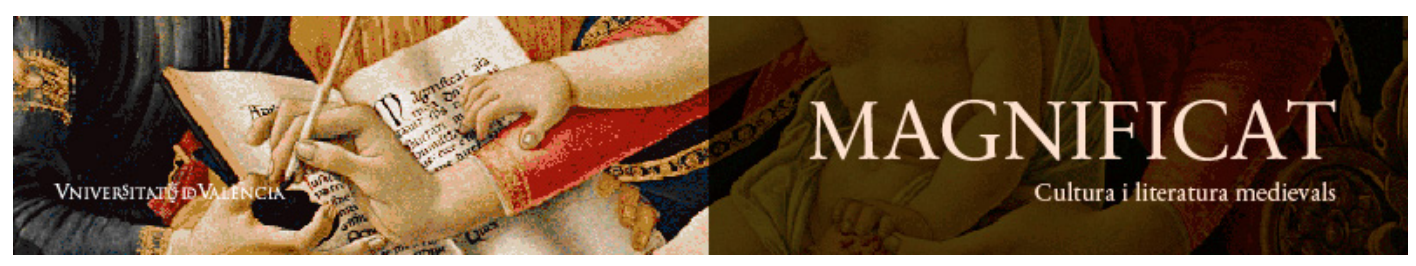

Magnificat Cultura i Literatura Medievals 8, 202I, 185-200. http://ojs.uv.es/index.php/MCLM

ISSN $2386-8295$ 
RESUMEN

Estudio y catalogación de La coronación de Nuestra señora (ID oII6, siglo xv) de Fernán Ruiz de Sevilla. Sus dos testimonios (el manuscrito PN6 y el incunable Cancionero de Ramón de Llavia, 86* RL) presentan numerosas variantes y variaciones entre sí. Este estudio permite arrojar luz sobre el proceso de transmisión del poema, y plantea hipótesis relativas a la filiación de las fuentes.

PALABRAS CLAVE

Fernán Ruiz de Sevilla; Cancionero de Llavia; variantes; imprenta incunable; tradición manuscrita

Natalia Anaís Mangas Navarro. 202I. 'La coronación de Nuestra Señora de Fernán Ruiz de Sevilla (ID oII6): variantes y variaciones', Magnificat Cultura i Literatura Medievals, 8: I85-200, DOI: $\underline{\text { https:// }}$ doi.org/IO.7203/MCLM.8.20960 (G) B

Este trabajo se enmarca en el proyecto Cancionero, romancero y fuentes impresas, del Ministerio de Economía, Industria y Competitividad (FFI2OI7-863I3-P), financiado por la Agencia Estatal de Investigación (AEI) y el Fondo Europeo de Desarrollo Regional (FEDER/UE), cuyo investigador principal es Josep Lluís Martos.

\section{TABLA DE CONTENIDOS}

I Estudio - ${ }^{8} 7$

${ }_{2}$ Conclusión - 197

3 Obras citadas - 199 


\section{Estudio}

La coronación de Nuestra Señora (ID oII6), de Fernán Ruiz de Sevilla, es un poema de limitada transmisión textual, pues únicamente aparece recogido en dos testimonios: el manuscrito PN6 (ff. I3 $6^{\text {ra }}$-I37 $7^{\text {bb }}$ ) (Dutton I990-I99I, III: 380 ) y el temprano incunable del Cancionero de Ramón de Llavia $\left(86^{*} \mathrm{RL}\right.$ ) (ff. 86 ${ }^{\mathrm{ra}}$-88 ${ }^{\mathrm{rb}}$ ) (Dutton I99O-I99I, v: 7). El primero está datado en la última década del siglo XV (ca. I490), ${ }^{\mathrm{I}}$ mientras que el segundo se editó en Zaragoza, por Pablo Hurus, en un arco de fechas que oscila entre I486 y I 490 (López Casas 2020: I36), aunque Dutton, sin justificarlo, se inclina por el año I 486. ${ }^{2}$ Ambas fuentes son, por tanto, muy cercanas en el tiempo, aunque, a tenor de estos datos cronológicos, PN6 se copiaría muy poco después de la impresión de $86^{*} \mathrm{RL}$. Ello no implica, en cualquier caso, que la fuente directa del manuscrito fuese algún ejemplar del Cancionero de Llavia,${ }^{3}$ sobre todo si tenemos en cuenta la existencia de otro testimonio impreso que menciona Daniel Devoto, del que, sin embargo, éste no aporta datos sobre la localización ni referencias bibliográficas. Hemos comprobado que tampoco está catalogado en los repertorios canónicos de poesía de cancionero y pliegos sueltos (Rodríguez-Moñino I97O; Dutton I99O-I99I; RodríguezMoñino et al. 1997). Por su parte, Devoto se ciñe, prácticamente, a las características tipográficas del impreso, que, curiosamente, conoce a través de Rodríguez-Moñino:

Gracias a la generosidad de don Antonio Rodríguez-Moñino, dispongo de un nuevo texto de este poema, que es -en general- más claro que el que incluye el Cancionero de Llaviá [sic]. Se trata de un pliego gótico de i6 páginas, sin lugar ni año, que tampoco lleva nombre de autor. La portada, ornamentada por orlas y por tres grabaditos de madera, reza:

Assunta es maria sup coru angelorum

Nueua coronacion. Fecha por vn deuoto...

(Devoto I975: 37-38)

Devoto indica que se trata de un nuevo texto del poema, lo que se evidencia también por el título que figura en ese pliego, Nueva coronación..., frente al que aparece en $86^{*} \mathrm{RL}$, Una coronación... Ello apunta, quizás, a que el pliego recoge una reelaboración o versión del texto que transmite $86^{*}$ RL. Devoto también aclara que ese nuevo poema es, en general, más claro que el que se incluye en el Cancionero de Llavia, refiriéndose, posiblemente, a los errores de imprenta o lecturas deturpadas que presenta $86^{*}$ RL y que aparecen subsanados en el texto que transmite el pliego. Estos escuetos datos apuntan a que la impresión de ese testimonio es posterior al Cancionero de

I. Fecha que consigna el Cancionero Virtual, mientras que BETA propone alrededor de I5Oo (manid 2705).

2. Benítez Claros llevó a cabo la primera edición del Cancionero de Llavia (1945) a partir de uno de los ejemplares conservados en la BNE (I-2567), que transmite un texto manipulado y falsificado en sus folios finales (López Casas 2O2O: I45-I46). Martín Abad (2OI4: I38-I39) concluye, tras su estudio, que Benítez Claros no sólo se basó en este ejemplar, sino también en el Cancionero castellano del $x V$ de Foulché Delbosc, así como en ediciones postincunables de Las setecientas de Pérez de Guzmán. Por tanto, a la luz de estos datos, «no hay que fiarse de dicha edición [...]. Es mejor recurrir al cancionero original en un ejemplar fiable que a la edición de Benítez Claros» (López Casas 202O: I46).

3. Existen seis ejemplares de esta edición incunable de $86^{*}$ RL: Biblioteca del Real Monasterio de San Lorenzo de El Escorial (32-I-I3); Biblioteca Nacional de España (I-2567, I-2892); British Library (IB. 52I63); Österreichische Nationalbibliothek (INC. I8.C.I8); y Bibliotheque Nationale de París (RES-YG-I4). Para el estudio material de la edición, así como de los tres ejemplares conservados en bibliotecas españolas, véase López Casas (202O: I3I-I58). 
Llavia, lo que no implica, en cualquier caso, que su estadio textual no sea anterior a $86^{*} \mathrm{RL}$, al igual que ocurriría con el manuscrito PN6, copiado poco después de la edición del Cancionero.

Respecto a la autoría del texto, solo en el cancionero incunable se atribuye a Fernán Ruiz de Sevilla. Los datos que conocemos sobre este autor son escasos, pues se reducen a los que advertimos, precisamente, en la rúbrica de 86*RL. Méndez Bejarano (I922-I925: 2, 339) señala que fue natural de Sevilla, ciudad donde vivió en el siglo XV. En el título que figura en el cancionero se le atribuye, además, la denominación de «bachiller», lo que nos revela cierto nivel cultural. No obstante, debió de haber obtenido ese grado en alguna de las universidades españolas que funcionaban durante la centuria del XV, pues los pasos para la construcción de la Universidad de Sevilla no comienzan hasta el año I5O2, cuando los Reyes Católicos emiten una cédula que autoriza su fundación. En cualquier caso, resulta difícil discernir si ese dato formaba parte de la propia firma del autor, como sugiere Méndez Bejarano, o si es fruto del compilador del cancionero, que pudiese conocer, de manera directa o mediata, al poeta.

Resulta especialmente llamativo que un autor tan desconocido comparta espacio en un cancionero con autores de prestigio del siglo XV, como Fernán Pérez de Guzmán, Juan de Mena o fray Iñigo López de Mendoza, cuyas obras, además, se caracterizan por una copiosa representación en otros cancioneros impresos y manuscritos. Fernán Ruiz, de hecho, es el único poeta de esta colectánea del que desconocemos datos biográficos y al que únicamente podemos atribuir la autoría de La coronación de Nuestra Señora. Si atendemos, sin embargo, a la temática de los poemas recogidos en $86^{*} \mathrm{RL}$, así como al propósito que buscaba el compilador, la composición de Fernán Ruiz encaja dentro de la línea didáctico-moral y religiosa que caracteriza al cancionero; ${ }^{4}$ sin duda, debió de ser esta la razón inexcusable que llevaría a Llavia a incluir La coronación. ${ }^{5}$

Los dos testimonios conocidos que recogen el texto presentan numerosas variantes y variaciones de distinta etiología que, en algunos casos, resultan difíciles de catalogar. Tanto el copista de PN6 como los diferentes agentes que participan en el proceso editorial de $86^{*} \mathrm{RL}$, introducen errores involuntarios o mecánicos, pero también -aunque en menor grado- lecturas divergentes de importante calado que apuntan hacia modificaciones conscientes. Si bien el corrector de imprenta era la persona que más intervenciones realizaba ${ }^{6}$ su figura no es frecuente en la imprenta temprana, como parece ser que ocurre en el Cancionero de Llavia; el intervencionismo, por tanto, estaría a cargo del amanuense que preparaba el original de imprenta manuscrito. En cualquier caso, no podemos descartar las variantes de autor, así como fenómenos de variación relacionados con la transmisión textual manuscrita (Martos 2OI7: 9). El estudio y catalogación de las variantes que presenta el poema nos permitirá discernir si ambos testimonios están emparentados o si, por el contrario, provienen de arquetipos textuales distintos. Debemos tener en cuenta, también, las intervenciones de una mano posterior en PN6, que introduce enmiendas coincidentes, en algunos versos, con las lecturas que transmite el incunable $86^{*}$ RL. Ello no implica una lectura o cotejo

\footnotetext{
4. Así lo afirma el propio editor en el prólogo del Cancionero: «Ca honesto : e buen deseo parece que | yo quiera que sepan los que leeran este libro : mi diligencia | en haver escogido de muchas obras catholicas puestas por | coplas : las mas esmeradas : e perfectas» (Real Biblioteca del Monasterio de El Escorial, 32-I-I3, f. Ir). La selección de poemas que realiza Ramón de Llavia evidencia que la antología se erige como un libro de lecturas para la educación de mujeres, no solo por la temática didáctico-moral de las composiciones, sino también por los textos que están dirigidos explícitamente a damas (López Casas 202I).

5. Para el estudio literario de los decires que recoge el Cancionero de Llavia, véase Martínez Pérez 2O2O: 25-270.

6. «El corrector [...], era quien más intervenciones realizaba en el texto. Con frecuencia lo hacía ya en la preparación del original de imprenta y luego, por supuesto, reiteradamente a lo largo del proceso de impresión, revisando las formas y los pliegos que se iban componiendo. Y en no pocas ocasiones tratará de ajustar o sortear las recomendaciones del censor oficial, no dudando en trastocar, enmendar, trasponer, añadir o incluso suprimir texto» (Pérez Priego 20I4: I60).
} 
directo entre el impreso y el manuscrito para esas correcciones, pues se trata de errores fácilmente detectables que no generan, en ningún caso, nuevos significados (enmiendas que subsanan la agramaticalidad o erratas frecuentes en el proceso de copia). ${ }^{7}$

Lo primero que llama la atención, por evidente, es la diferente extensión de un testimonio y otro: mientras que en $86^{*}$ RL presenta 53 estrofas, en PN6 se copian únicamente r9, de manera que el manuscrito transmite una versión mucho más breve que el impreso. Como ya advierte Martínez Pérez (2O2O: 258), coinciden entre sí hasta la estrofa I6; la I7, presente en Llavia, no aparece en el manuscrito, y las tres restantes de PN6, esto es, la I7, I8 y I9, se corresponden con la I8, I9 y 20 en $86{ }^{*}$ RL. Este salto de estrofa apunta a un caso de homoioteleuton, fenómeno frecuente en los procesos de copia.

El poema se interrumpe en PN6 justamente cuando termina la sección dedicada a los instrumentos, lo que indica, quizá, que el copista tuviera un especial interés en esa parte concreta. La versión recogida en el pliego que menciona Devoto debía de ser, incluso, más larga que la que presenta $86^{*}$ RL, aspecto que se evidencia por el número de páginas que contiene (I6) y porque la parte referente a los instrumentos comienza en la estrofa I9, introducida por una rúbrica interestrófica: «Comiençan los ynstrumentos que lleua / nra señora en la asuncion» (Devoto I975: 38); mientras, en PN6 y Llavia es en la copla I9 y 20, respectivamente, cuando termina la enumeración de los instrumentos musicales.

Cabe señalar que ambos testimonios presentan una coincidencia desde el punto de vista gráfico: el uso sistemático del signo tironiano. Como advierte López Casas (2020: I39), su empleo se extiende a lo largo de todos los poemas del Cancionero de Llavia, a excepción del prólogo y de la tabla inicial, donde se alternan la conjunción e y el signo tironiano. Al margen de esta concurrencia, hay notables variantes gráficas o fonéticas: v. 5: nocturno (86*RL) / noturno (PN6), meydad/ meytad; v. 6o: sacrana (86*RL) / sachrana (PN6); v. 67: apocalipsi $\left(86^{*} \mathrm{RL}\right) /$ apocalibsy (PN6); v. 72: milagros (86* RL); miraglos (PN6); v. 76: egyptianos (86*RL) / egiçianos (PN6); v. 9I: seya $\left(86{ }^{*} \mathrm{RL}\right) /$ sea $(\mathrm{PN} 6)$; v. 92: ca $\left(86^{*} \mathrm{RL}\right) /$ qua (PN6); v. IOI: sabaoth $\left(86^{*} \mathrm{RL}\right) /$ sabaod (PN6); v. II2: humildad (86* RL) / umilldad (PN6); v. II9: instrumentes $\left(86^{*} \mathrm{RL}\right) /$ estrumentes o estrumentos (PN6). ${ }^{8}$

Como se puede observar, el manuscrito tiende con más frecuencia -al menos en esta obra- a grafías latinizantes (qua por ca), así como a conservar el grupo consonántico latino ch, a excepción de la palabra coros, mientras que en el impreso advertimos siempre la variante gráfica choros (ej., v. IO5). En PN6 está extendido el uso de la cedilla, en contraste con el impreso, que alterna la doble $c$ o la $z$. Cabe señalar, también, que el copista de PN6 prescinde, con frecuencia, de la virgulilla de la $\tilde{n}$, lo que nos da como resultado palabras como anafil, en lugar de añafil (v. 7) o estranas frente a estrañas (v. 9). Finalmente, en PN6 destaca el uso sistemático de la doble rr en posición inicial de palabra: rraçones, rreynante, rreverençia.

Las ig estrofas que comparten 86 * RL y PN6, sin excepción, contienen variantes de distinta naturaleza y entidad. De entrada, las rúbricas de ambos testimonios difieren notablemente, hasta el punto de que, si atendemos únicamente a este aspecto, podríamos pensar que nos encontramos ante dos composiciones distintas:

7. Advertimos ocho intervenciones del lector posterior: en el v. Io introduce el artículo determinado el; en el v. I4 corrige la palabra septentrionales; en el v. ig añade la -s del plural a la palabra copioso para subsanar la discordancia gramatical de número; en el v. 78 actúa al contrario, tachando la -s final de dellas para que el pronombre concuerde con su sustantivo, fiesta; en el v. 8I introduce el artículo los y la conjunción y; en el v. 82 añade el artículo los; en el v. I39 introduce la preposición de antes de charamella; en el v. I4I, en cambio, la tacha antes de lonbarda, subsanando la aparente hipermetría.

8. Para la caracterización lingüística de los textos únicos y versiones en el Cancionero de Llavia, véase De Beni 2O2I. 
$86 *$ RL

Una coronación de nuestra señora fecha por el bachiller fernan ruyz de seuilla (f. $\left.85^{\text {ra }}\right)$

\section{PN6}

Dezir de la asençion de santa maria $(\mathrm{f}$. $\left.\mathrm{I} 36^{\text {ra }}\right)$

En el Cancionero de Llavia se intitula el texto como coronación de nuestra señora, frente a asençion de santa maria en PN6. Ambos conceptos, aunque están estrechamente relacionados, no se refieren a un mismo hecho, pues la Asunción es el momento que precede a la Coronación: la Virgen María es llevada en cuerpo y alma al cielo, donde es coronada por Jesucristo. Al margen de esta llamativa variación en la rúbrica, PN6 presenta un error en la palabra «asençión», atribuible a un despiste frecuente en que incurren los copistas, como es la sustitución de un grafema por otro. Por otro lado, es en PN6 donde se incluye la identidad genérica de la composición, el decir, ${ }^{9}$ pero ninguna referencia a la autoría.

Entre ambos testimonios advertimos variantes vinculables a los procesos de composición tipográfica y copia, como la omisión, adición o sustitución de nexos, conjunciones y artículos:

\section{$86^{*} \mathrm{RL}$}

$\begin{array}{ll}\text { V. IO } & \text { omit. el } \\ \text { v. 2I } & \text { y conjuntamente } \\ \text { V. } 29 & y \text { por este verso } \\ \text { v. } 76 & \text { y a egyptianos plaga fue puesta } \\ \text { v. } 83 & \text { los sus movimientos }\end{array}$

\section{PN6}

sonava la una en el oriente ${ }^{\text {Io }}$

omit. y por aqueste berso a egiçianos la plaga fue puesta omit. sus ${ }^{\mathrm{II}}$

En cualquier caso, estas variantes no conllevan una alteración en el significado del verso, como se puede apreciar en los ejemplos citados y, al tratarse de un decir en coplas de arte mayor, la cuestión de la hipometría o hipermetría queda relegada a un segundo plano, en pos del esquema acentual. Así, aunque predomina claramente el verso dodecasílabo, en algunos casos advertimos endecasílabos o decasílabos que se ajustan al patrón definido por Lázaro Carreter (I972: 343-378) y que, recientemente, ha profundizado Gómez Redondo (20I6): los dos períodos (hemistiquios) que constituyen el verso alternan la secuencia acentual de un pie rítmico ternario (un dáctilo, óoo) y uno binario (un troqueo, óo). ${ }^{12}$

Mayor complejidad entrañan las preposiciones, pues su omisión o adición, así como la sustitución de una preposición por otra categoría gramatical, sí pueden implicar alteraciones semánticas,

9. El decir es uno de los géneros más cultivados en la poesía cancioneril castellana, caracterizado por su flexibilidad temática y formal, en contraste con otros géneros más rígidos, como la canción, la esparsa o las preguntas y respuestas. Los metros que predominan en el decir son el octosílabo, que suele combinarse con quebrados tetrasílabos, y el verso de arte mayor (Chas Aguión-Álvarez Ledo 20I6: 65I). En este caso, el poema de La coronación está formado, en su mayoría, por octavas de versos dodecasílabos, con la siguiente secuencia de rimas: ABAB BCCB (Martínez Pérez 2O2O: 259).

IO. El artículo determinado «el» es añadido por el lector posterior.

II. Otros ejemplos de este tipo, en los vv. 2, 5, I3, I5, 35, 36, 39, 68, 77, 8I, 82, 90, 99, IO2, I24.

I2. El verso puede sumar entre diez y catorce sílabas, siempre que se cumpla ese patrón acentual. En este sentido, el abanico de posibilidades es muy amplio, ya que no es necesario que ambos hemistiquios presenten una cadencia equivalente. Ello da lugar a distintas secuencias rítmicas dentro del mismo verso, que pueden distribuirse en dos hexasílabos $(6+6)$, un pentasílabo y un hexasílabo o viceversa $\left(5^{+6}\right.$ o $\left.6^{+} 5\right)$, la combinación de heptasílabos con pentasílabos $\left(7^{+} 5^{\circ} 5^{+} 7\right)$ y dos pentasílabos $\left(5^{+} 5\right)$ (Gómez Redondo 20I6: 490). 
aunque generando, en la mayoría de los casos, lecturas equipolentes, a excepción del v. 4, que va precedido del verbo llamando y, por tanto, requiere la lectura que presenta el impreso:

\section{$86^{*}$ RL}

v. 4 al grand fundamjento

v. 39 al grand carlo magno

v. 46 de mi mano derecha

v. 56 en el firmamento

v. 59 y vi en el divino

v. 90 en tres de las ordenes

v. IO4 do justo se cubre

v. IIO con grand excellentia

v. $120 \quad y$ angelical

\section{PN6}

del gran fundamiento

el gran carlo magno

$a$ mi mano derecha

con el firmamento

omit. en

$c a$ tres de las ordenes

de justos se cubren

$y$ gran eçelençia

en anjchical $^{13}$

Las variantes por omisión de letras también pueden derivar en lecturas que implican distinciones en el número y género de los sustantivos, artículos o adjetivos: (v. 26): aguas (86* RL) / agua (PN6); (v. 82): todas sus climas (86* RL) / todos los climas (PN6): ;4 (v. IO3): «de tu majestad y toda memoria» (86*RL) / «de tu majestad y todos memoria»; (v. I28): de sus perfectiones (86* RL) / de su perfeçion (PN6). En ocasiones, el uso del singular o plural afecta al verbo y, por ende, también a sus complementos: (v. 48): «para el bueno quando muriere» (86* RL) / «para los buenos quando muerieren» PN6; (v. 49): sustente (86*RL) / sustenten (PN6); (v. IO4): «do justo se cubre con el tu sombrero» (86*RL) / «de justos se cubren con el tu sombrero» (PN6).

La sustitución de una palabra o conjunto de palabras genera, en algunos casos, significados nuevos, pero que podemos catalogar como lecturas equipolentes, pues adquieren, indistintamente, pleno sentido en el verso:

\section{$89^{*}$ RL}

V. II sonaba la una de las tres tamañas

v. I6 que en las escuchar fuy bien diligente

v. I7 Finidos los modos de los añafiles

v. I8 angelicas vozes quatro començaron

v. 2I $y$ conjuntamente todas mostraron

v. 27 gracias bendiciones salud in superno

v. 3I magnificas laudas con voz infinita

v. $37 \quad$ ytodos aquellos que mares y rios

v. $3^{8} \quad$ so si sojuzgaron poniendo pelea

v. 45 y quien lo fiziere y suplico fuere

v. 55 gracias bendiciones

v. 69 obedeciendol su fazedor

v. Io9 tu sosteniste la fe y oviste

\section{PN6}

sonaba la una de las tras montanas en las escuchando fuy bien diligente Oydos los modos de los añafiles angelicas boçes quatro concordaron conjuntamente todas demostraron gracias bendiciones saber bien superno magnificas laudes por bos infinita aquellos que tierras y mares y rrios asy sojuzgavan poniendo pelea $y$ si lo fizieren y supliçes fueren virtudes y graçias yobedençia al su fazedor tu lo sotentaste la fe y obiste

I3. Otros ejemplos donde puede advertirse la omisión, adición o sustitución de preposiciones en los vv. 2, 26, 28, 94, I25.

I4. El artículo determinado masculino plural es un añadido del lector posterior. 
Menos frecuentes son las alteraciones o trasposición en el orden de palabras, pues únicamente hemos localizado tres ejemplos, que, en cualquier caso, no suponen variantes significativas. Este tipo de metátesis léxica podría atribuirse a fallos memorísticos del cajista y el amanuense:

\section{$86^{*}$ RL}

v. 85

V. I2I

V. 128 cantauan canciones graciosas y rimas suenen quebradas e guebas $y$ oquetas los sabios los viejos $y$ los entendudos

\section{PN6}

cantauan graçiosas cançiones y rrimas suenen quebradas $y$ globas uquetas los sabios $y$ uiejos y los entendidos

También advertimos algunos casos donde la sustitución de una palabra por otra genera variantes adiáforas, ofreciéndonos, en varios versos del manuscrito, lecciones latinizantes o cultismos. Este tipo de variantes sí apuntan hacia una intervención consciente en el texto:

$86^{*}$ RL

v. 25 dios padre reynante siempre eterno

v. 35 rey alexandre pontifices romanos

v. 88 las ordenes ultimas medios y primas

v. 108 tu lo tetaste y tu lo pariste

\section{PN6}

dios padre reynante siempre coeterno rey alexandre pontifex romanos las ordenes ultimas medianas y fimas tu lo lataste y tu lo pariste

En el segundo caso, además, la sustitución de un vocablo por otro afecta también a la métrica: en $86^{*}$ RL, el v. 35 es dodecasílabo, frente al endecasílabo de PN6, pero ambos casos se ajustan a los posibles esquemas acentuales de la poética del arte mayor. En el v. 88, el manuscrito lee medianas, en contraste con la palabra medios que presenta el impreso, que, a su vez, se trataría de un error tipográfico, pues la lectura correcta sería medias, ya que el sujeto de la oración es femenino: «las ordenes ultimas medias y primas». El último ejemplo, que es el más llamativo de los cuatro, se explica por la tendencia en el manuscrito a prescindir de la $c$ en el grupo consonántico $c t$ (por ejemplo, noturno o efetualmente). Se trata, por tanto, de la palabra lactaste, es decir, dar leche o amamantar, en efecto, una lectura análoga a tetaste, pero en su vertiente culta.

El impreso presenta errores tipográficos que también podemos atribuir al proceso de composición. Los más habituales son los errores del cajista, de tipología diversa, que pueden deberse a una mala lectura del manuscrito o fallos de memoria, así como errores mecánicos, como confusión de grafías, metátesis y adición u omisión de letras o palabras (Martos 2OI3: I23-I25). En el v. I 4 leemos setrentionales, un claro caso de metátesis gráfica que, además, no recoge el CORDE en su base de datos (como sí ocurre, por ejemplo, con otros casos de metátesis frecuentes documentadas, como prelado por perlado). Otro ejemplo de este fenómeno se advierte en el v. $3^{2}$, en la palabra preverso, en lugar de perverso.

En el manuscrito también encontramos errores paleográficos y poligenéticos, generados en el proceso de copia. En el v. I4, el amanuense copia sentrionales, pero la mano de un lector posterior introduce, en la parte superior de sen, la sílaba te, lo que indica que advierte el error. En el v. 84 localizamos la lectura çines y çimas, frente a fines y cimas del impreso, entendiendo fines como «límite» 0 «confín»; o en el v. 88, fimas, en lugar de primas; caso parecido ocurre en el v. I3I, lonbarda, en lugar de bombarda (aunque podría tratarse también de una lectio facilior), pues en la estrofa se hace referencia a instrumentos musicales; o en el v. 57, que encontramos previno, frente a la lectura correcta del impreso, provino, pues alude a la venida del amanecer. En otros casos, el 
error del copista lleva a la ruptura de la rima, como en el v. 96: los cantos entonan, frente al entonen de $86^{*} \mathrm{RL}$; o en el v. 42, los comprendieron, en lugar de les comprehendiere, como lee $86^{*} \mathrm{RL}$.

Si atendemos al usus escribendi del copista, observamos que, para el grupo consonántico ps, se decanta por la consonante oclusiva sonora, bs. En el v. 65, «no vi padeçer las planetas y clisy» (clipse en $86^{*} \mathrm{RL}$, caso de aféresis por eclipse), todo apunta a que el amanuense, por error, olvida la $b$, pues después escribe, correctamente, apocalibsy. La omisión de grafías, debido a descuidos en el proceso de copia, también puede romper la concordancia gramatical del verso: ledad critatura, frente a criaturas en $86^{*} \mathrm{RL}$ (v. 32). Por otro lado, la omisión de palabras puede generar casos de hipometría, como ocurre en el v. 32: «y entendi lo que manifestaron», frente a la lectura que recoge $86^{*}$ RL, con otro verbo al principio del verso: «oy y entendi lo que manifestaron». También podemos advertir variantes que generan hipermetría, como en el v. 87: «los coros angelicos y la jerechia», en contraste con choros angelos en el impreso; finalmente, cabe destacar los errores de copia que dan como resultado lecturas sin sentido, debido a los descuidos del amanuense, como ocurre en el v. IOO: «esta sento y dios verdadero», frente a la lectura correcta de 86 * RL: «o santo santo o dios verdadero».

En ocasiones, el copista introduce modificaciones que parecen ser voluntarias, pues debió de considerar errónea la lectura presente en su antígrafo. En el v. i27 encontramos la palabra entendidos en posición final, mientras que $86^{*} \mathrm{RL}$ transmite entendudos; de esta manera, el copista de PN6 no solo rompe la rima de la segunda semiestrofa (en -udos, agudos), sino que cree enmendar un error. Sin embargo, como explica De Beni, se trata «de una huella de participio pasado (aquí nominalizado) en -udo, un modelo de sufijación que ya estaba en pleno declive en el Cuatrocientos y que se conserva al amparo de la rima» (2O2I). Por otro lado, en el v. 66 advertimos el concepto luminarias, frente a la lectura que presenta el impreso, luminarios. Podría tratarse -en caso de que su antígrafo fuese $86^{*} \mathrm{RL}$ u otro testimonio manuscrito que presentara esa lectura- de una enmienda, debido al desconocimiento del término luminarios, pues no está recogido ni en el Diccionario de autoridades ni en el DRAE. Sin embargo, el CORDE documenta once casos $\mathrm{y}$, por el contexto, todo apunta a que se trata de una forma plural del sustantivo luminar, aunque poco frecuente: «Qualquiera de los Astros Celestes, que despide de sí luz y claridad. Llámense assí regularmente el Sol y la Luna» (Aut. s.v. luminar). Esta es la acepción que encaja en el sentido de la estrofa completa -pues antes hace referencia a los planetas y al eclipse- y no la de luminarias ('luz' o 'lámpara'), como transmite PN6.

La sustitución de una palabra por otra puede generar en el manuscrito errores de mayor calado que los expuestos anteriormente, así como lecturas privativas, siendo el impreso el que presenta la lectura correcta:
$86^{*}$ RL
V. I
Mundanos desseos me no ocupando
V. 43 del infernal fuego dolor infinito
v. $5^{8}$ la diornal ora y alua cercana
v. 75 y purificaste aquel daniel
v. II5 espacificadas que dios infinable

\author{
PN6 \\ Mundanos desseos me van ocupando \\ en infernal fuego poder infinito \\ la diuinal ora y alua cercana \\ y purificaste aquel diuinal \\ espacificadas que dios inefable
}

El íncipit del poema se debe analizar en relación al siguiente verso, «velando y orando la su deydad». En este sentido, la lectura correcta es la que transmite el Cancionero de Llavia, pues el poeta se encuentra velando y orando y no está ocupado en cuestiones mundanas, como sugiere el significado que presenta el manuscrito: me van ocupando. En el v. 43, el contexto exige, claramente, 
dolor infinito, pues hace referencia al infierno, así como en el verso siguiente se alude a ese dolor como la pena impuesta; no cabe, por tanto, la lectura que recoge PN6. En el v. 58, el alua cercana es la diornal ora, y no la divinal ora, aunque esto podría explicarse como un error del amanuense debido al cruce o atracción de palabras del verso siguiente (en este caso, divino). En el v. 75 también advertimos divinal en el manuscrito, aunque este error no podría explicarse por cercanía de otro verso, sino por una mala lectura del copista. En esta línea se justificaría también la sustitución de inefable por infinable.

Por el contrario, el impreso $86^{*}$ RL presenta errores que, sin embargo, aparecen enmendados en PN6, así como lecturas para las que el manuscrito propone una variante más acertada dentro del contexto del verso y los versos contiguos:

$86^{*}$ RL

v. 35 Assi europa y los affricanos

v. 63 vi majestad y nunca vi preto

v. $7^{2}$ oyan mjlagros y oyan sabor

v. 79 o gracias te pido dispulso vinomjo

v. I26 santas compañas

\section{PN6}

Assia europa y los africanos vi claridad y nunca vi prieto oya miraglos y aya sabor o gracias te pido espulso el demonio altas compañas

En el primer caso, si interpretáramos assi como adverbio y fuese seguido de coma, haciendo referencia al modo en que Europa y los africanos van a asistir a la Coronación de la Virgen, podría tener sentido. Sin embargo, la lectura que presenta más sentido es la que transmite el manuscrito, con la enumeración de los tres continentes hasta el momento conocidos. El segundo ejemplo es muy peculiar, lo que revela que, si el copista de PN6 usó como fuente directa 86* RL, detectó sutiles errores y procedió a su enmienda; por el contrario, cabe la posibilidad de que el antígrafo del manuscrito fuese un testimonio hoy perdido, que contenía ya las lecturas existentes en PN6. La variante majestad carece de sentido en ese verso, pues tanto el anterior como el posterior enumeran una secuencia de antítesis. Así, lo correcto es claridad, en contraste con prieto, entendiéndose como 'oscuro' (aunque en el impreso se lee preto, lo que podemos catalogar de error por omisión de letras atribuido al cajista). La lectura del v. 72 que ofrece $86^{*} \mathrm{RL}$ es agramatical (oyan mjlagros y oyan sabor), pues el sujeto, presente en el verso anterior, es vuestro entendimiento, lo que exige la concordancia del verbo en singular, como ofrece PN6, que, además, enmienda acertadamente oyan por aya. El cuarto caso es un claro error que deja en evidencia la torpeza del cajista, lo que nos da como resultado un verso sin sentido. Finalmente, en el v. I26, el impreso lee santas compañas, frente a altas en PN6. Quizá, podría interpretarse como lectura equipolente, pero el verso anterior, «en las ciencias santas y santos», apunta hacia una variante de imprenta, errónea en este caso, pues se confunden las palabras de dos versos contiguos; el copista, para evitar la repetición, restaura santas por altas. En algunos casos, el manuscrito ofrece una lectura alternativa al impreso, en un intento, quizá, de enmienda, pero sin llegar a generar una variante convincente, como ocurre en el v. I28: «de sus perfectiones anbienes a tantos» / «de su perfeçion y dones a tantos» (PN6).

Más allá de la variante, encontramos variaciones de calado en versos completos o semicompletos, lo que da lugar a dos secuencias distintas en ambos testimonios y, por tanto, a dos significados e interpretaciones diferentes: 


\section{6* RL}

v. 44 les pongo por pena quien no lo criere

v. 95 los choros offician disituacion

v. II8 te leen luego los choros siguientes

\section{PN6}

les pongo por pena sy no lo cumplieren los tronos ofiçian diçen su cançion y luego los otros choros siguientes

Con todo, las últimas tres estrofas de PN6, que se corresponden con la I8, I9 y 20 en $86^{*}$ RL, son las más peculiares, pues presentan una acumulación de variantes significativas, especialmente en lo que respecta a la nomenclatura de los instrumentos. Las divergentes lecturas en estos versos, unido a los ejemplos expuestos anteriormente, nos lleva a pensar que los testimonios no están emparentados:

\section{$86 *$ RL}

Jugauan de arpa y de chernubela gujtarra xabeua de buen añafil de tuca bombarda de quarta viuela de lyra de flauta dulcanya gentil laud monicordio escaquer donegil organos timpano choro baldosa vihuela de arco y rota graciosa musica trompa de paris sotil

Las trompas panderos adrufes sonajes eran de todos los otros tenores bioresas fazian y muchas trebajas con los atabales y con los atanbores la gayta palillos bandurria dulçores rabe zinfonia salterio canon la cytola con el agaripe a su son con el duacorde le dan sus loores

De los instrumentes que aqui sobre seo $y$ de sus tantas diuersas fechuras si aqui se nombrassen sin duda yo creo que bien ocupassen asaz escripturas tocauan tenores de tantas figuras estampidas valadias y muchas cantiones motetes graciosos las tres legiones honrando la fiesta estas criaturas

\section{PN6}

Jugauan de harpa y de charamella guitarra xandoça de buen añafil de cuca lonbarda de quinta biuella de lira de flauta duncay jentil laud monacordio escanquil doñegil organos tynpano coro baldosa viuela darco y rroca graçiosa museta y tronpa de paris jentil

Las tronpas panderos adufles sonajas eran de todos los coros tenores buyresas fazian y otras trebajas con los atabales y los atambores la gayta palillos bandurria dulçores rrabe çinfonia salterio cañon la çytola con al garpe su son con el ditacordio le dan sus loores

De los esturmentos ca aqui sobre seo de sus tantas diversas fechuras que sy se nombrasen sin duda bien creo que se ocupasen asaz escrituras tocauan de tantas figuras estampidas baladas y tantas cançiones motetes graçiosos las tres rregiones onrrauan la fiesta estas criaturas

El uso de la voz chernubela podría referirse a churumbela, lo que nos lleva a una lección deturpada, generada, quizá por una mala lectura del original de imprenta o por falta de comprensión del término. Según el Diccionario de autoridades, para Covarrubias la palabra churumbela es de origen toscano, proveniente de ciarambela, concepto que se asemeja más a la lectura que transmite PN6 (charamella). Un caso similar, debido a un fallo de memoria en el dictado o a una mala lectura, se advierte en el v. I44: «Musica trompa de paris sotil». Quizá, el copista que prepara el original de imprenta, o bien el cajista, desconocía la palabra museta, o entendió música en su lugar, pero la variante que presenta más sentido en el conjunto de la estrofa es, en efecto, la que transmite el manuscrito, museta, pues hace referencia a un instrumento musical, como conviene 
en esta secuencia. ${ }^{15} \mathrm{Si}$ el copista tenía delante algún ejemplar del Cancionero de Llavia, enmienda conscientemente la lectura; de no ser así, su antígrafo podría haber sido un testimonio hoy perdido, un estadio intermedio entre $86^{*}$ RL y PN6 que, a su vez, también corrige los errores de 86*RL. El impreso presenta también, en estas estrofas, errores tipográficos que podemos atribuir al cajista: metátesis gráfica (v. I4O, dulcanya, en lugar, de dulçayna); sustitución de un tipo móvil por otro, lo que provoca la ruptura de la rima (v. I45, sonajes frente a sonajas); adición de letras (valadia por valada); omisión del signo de nasalización (v. I4I, doneguil en lugar de doñeguil).

En otros casos, es el impreso el que presenta una lectura más acertada, mientras que el manuscrito incurre en errores o variantes deturpadas, como ocurre en xandoça por xabeua. El término xandoça no aparece recogido en ningún diccionario, ni tampoco vocablos parecidos. En el Diccionario de comercio medieval, xabeua nos remite a la voz árabe ajabeba que, en efecto, es una flauta morisca; estamos, por tanto, ante un caso de aféresis en el impreso. La sustitución de una grafía por otra, debido a descuidos del amanuense en el proceso de copia, da lugar a variantes erróneas: lonbarda, en lugar de bombarda, o rroca, frente a rota ${ }^{16}$ En el v. I5O, el amanuense de PN6 copia cañón, frente a canon en $86^{*} \mathrm{RL}$. Al igual que en el caso de lonbarda, podría tratarse de una lectio facilior o, quizá, de una enmienda consciente, ya que el copista entendería canon en su acepción de composición musical y no de instrumento, procediendo, así, a su corrección. Sin embargo, la palabra canon era una de las múltiples variantes usadas para referirse al salterio (Porras Robles 2008: I20) -de hecho, se menciona justo después de este instrumento-, lo que apunta a la lectura correcta de $86^{*} \mathrm{RL}$. Para el caso de agaripe / al garpe, ninguna acepción aparece documentada en el CORDE, aunque es muy probable que ambos testimonios se refieran al galipe. Pedrell indica que podría tratarse de un instrumento árabe equivalente al tamboril (I9OI: $5^{6}$ ) mientras que Corominas, en su edición crítica del Libro de Buen Amor (1967: 462) propone que se trata de una danza o composición musical. ${ }^{17}$

Caso parecido advertimos con las variantes escaquer / escanquil, pues no aparecen documentadas en el CORDE ni en el Diccionario de autoridades. No obstante, $86^{*} \mathrm{RL}$ presenta la lectura que más se aproxima al instrumento al que parecen hace alusión, escaque, un órgano de cuerdas ${ }^{18}{ }^{8}$ En el caso de adrufes / adufles, todo apunta a que se refiere al adufe, «cierto género de tamboríl baxo y quadrado, de que usan las mugéres para bailar, que por otro nombre se llama pandéro» (Aut.s.v. adufe).${ }^{19}$ La lectura que presenta PN6, adufles, sí está documentada en el CORDE, no así la que

I5. La palabra museta aparece documentada en un poema que transmiten el Cancionero castellano de París (PN9), el Cancionero de Salvá (PNi3) y el Cancionero de Juan Fernández de Íxar: «por fuerça de la tronpeta / non por flauta nin museta» (CORDE, s.v. museta).

I6. La rota era conocida como arpa-salterio, al tratarse de un instrumento híbrido que poseía características comunes a ambos: del arpa toma la disposición vertical y la técnica de la cuerda pulsada, mientras que del salterio adopta la caja triangular de lados rectos, los rosetones resonadores y los puentes (Porras Robles 2008: 130).

17. A raíz de los VV. I33O-I343: «medio canón e harpa, / con el rabé morisco; entre ellos alégrase el galipe francisco; / la flauta diz con ellos, más alta que un risco, / con ella el taborete; sin él non vale un prisco».

I8. Podría tratarse de un préstamo del francés antiguo, eschaquier (hoy échiquier, 'tablero de ajedrez’), aunque también de un préstamo del catalán o del occitano o, incluso, de una palabra aragonesa. Debemos tener en cuenta que el incunable se editó en Zaragoza y, aunque el aragonés ya estaba en claro retroceso, es probable que todavía se mantuviesen algunos rasgos lingüísticos. En el caso del catalán, por ejemplo, se conserva actualmente con la misma grafía que figura en el impreso (escaquer). Se documentan muchas referencias de escaques en la poesía de cancionero. Destacamos la que aparece en un poema de Francisco Imperial, recogido en el Cancionero de Baena: «con los estormentos que dulçe tocavan, harpas e escaques que más acordaban» (Dutton y González Cuenca 1993: 267).

19. Como muestra un ejemplo extraído del Picatrix traducido al castellano por orden de Alfonso X: «En el segundo grado sube una muger que tiene en la mano adufle». Se registran otros dieciocho casos en seis documentos distintos, uno de ellos la General Estoria. El DRAE recoge la palabra adufre, que nos remite a s.v. adufe, un pandero morisco. 
transmite $86^{*}$ RL, pero sí adufres. Podría tratarse, por tanto, de una metátesis gráfica por error del cajista, así como de una mala lectura o falta de comprensión del término.

Ambos testimonios presentan en estas estrofas lecturas equipolentes que adquieren, indistintamente, sentido en el verso:

$86 *$ RL

$\begin{array}{ll}\text { v. I44 } & \text { trompa de paris sotil } \\ \text { V. I47 } & \text { y muchas trebajas } \\ \text { v. I52 } & \text { duacorde } \\ \text { v. I5 } & \text { y muchas cantiones } \\ \text { v. I59 } & \text { legiones } \\ \text { v. I60 } & \text { honrando }\end{array}$

\section{PN6}

V. I36 trompa de paris gentil

v. I39 y otras trebajas

v. 144 ditacordio

v. I5O y tantas canciones

V. 15 I rregiones

v. I52 onrrauan

Finalmente, advertimos variantes para las que no llegamos a comprender el sentido exacto del término o, al menos, aproximado, lo que nos impide dilucidar sobre cuál es la lectura correcta: cuca / tuca; ${ }^{20}$ bioresas / buyresas; o de quarta vihuela / de quinta vihuela. Emilio Pujol (I984: 2, n. 6) explica que se trataría de una vihuela de mano, en contraste con la de arco, mencionada en los versos siguientes. Respecto a la referencia quarta o quinta, en este caso, a partir de la lectura del Cancionero de Llavia, Pujol indica que «podría tratarse de una vihuela aumentada o reducida de tamaño en una cuarta proporción» (I984: 2, n. 6).

\section{${ }_{2}$ Conclusión}

Los dos testimonios conocidos que recogen La coronación de Nuestra Señora presentan numerosas variantes y variaciones de distinta naturaleza, lo que nos permite plantear algunas hipótesis sobre la filiación de las fuentes. En primer lugar, el objetivo de transmisión del poema es, a todas luces, distinto. La variación más importante reside en el número de estrofas, pues el texto que aparece en PN6 es una versión abreviada del poema completo que, presumiblemente, recoge el Cancionero de Llavia. Esto evidencia un interés del copista por una parte concreta de la obra, que se interrumpe al finalizar el espacio dedicado a los instrumentos. Ello no implica, en cualquier en caso, que ambos testimonios no estén emparentados, pues el copista de PN6 pudo tomar como antígrafo el impreso $86^{*} \mathrm{RL}$, y trasladar únicamente las coplas que suscitaran su interés.

Además de las variantes vinculadas directamente a los procesos de composición tipográfica y copia (metátesis gráfica, omisión o adición de letras o palabras y sustitución de un grafema por otro), existen otro tipo de variantes que revelan intervenciones conscientes. Así, pese a los yerros acumulados por despistes y torpeza del copista, advertimos en PN6 sutiles enmiendas que subsanan errores presentes en $86^{*} \mathrm{RL}$, lo que nos permite verificar que no siempre el impreso ofrece el mejor testimonio. Por otro lado, también encontramos variantes que, quizá, no responden a un intervencionismo, sino a una desconexión entre ambas fuentes. Tanto la rúbrica del poema como la parte dedicada a los instrumentos nos ofrecen lecturas muy dispares, lo que nos lleva a plantear la posibilidad de que los testimonios no están emparentados.

20. Podría tratarse, en ambos casos, de un error, atribuible al cajista y al copista; quizá, el término adecuado en estos versos es la tuba. 
A la luz de estos datos, por tanto, podemos aventurar dos conclusiones: por un lado, que el copista de PN6 tiene delante un modelo distinto a $86^{*}$ RL que ya contenía las variantes presentes en el manuscrito. Se trataría de un testimonio hoy perdido o no localizado de otras versiones manuscritas del poema que circulasen en el siglo XV y que, de igual modo, pudieron sufrir alteraciones en el proceso de transmisión. Por otro lado, también cabe la posibilidad de que el antígrafo de PN6 fuese el impreso $86^{*} \mathrm{RL}$, aunque el copista innova y enmienda allí donde considera que el texto que transmite el Cancionero de Llavia está deturpado, a veces con tino y, en otras, añadiendo nuevos errores o lecturas poco acertadas. Finalmente, resulta arriesgado, en este punto, proponer variantes de autor, debido al poco conocimiento que tenemos de Fernán Ruiz de Sevilla y de su obra, que se reduce, únicamente, a La coronación de Nuestra Señora. Estas conclusiones podrían abrir paso al estudio de la génesis de ambos cancioneros, tan dificil de esclarecer en muchos casos, debido a la procedencia de distintas fuentes para su compilación, de manera que es conveniente estudiar de forma individual a los autores y las obras. 


\section{Obras citadas}

Benítez Claros, Rafael (ed.). i945. Cancionero de Ramón de Llavia (Madrid: Sociedad de Bibliófilos Españoles)

BETA: Biblioteca Española de Textos Antiguos (versión electrónica del BOOST). 1984-. Charles B. Faulhaber, Ángel Gómez Moreno, David Mackenzie, John J. Nitti, and Brian Dutton Bibliography of Old Spanish Texts (Madison, WI: Hispanic Seminary of Medieval Studies) $<$ http://sunsite.berkeley.edu/Philobiblon/Beta> $>$ accessed IO-O2-2O2I]

Cancionero Virtual: An Electronic Corpus of $15^{\text {th }}$ Century Castilian Cancionero Manuscripts http:// cancionerovirtual.liv.ac.uk/

Chas Aguión, Antonio; Álvarez Ledo, Sandra. 20I6. 'Io.3.2 Los decires', in Historia de la métrica medieval castellana, ed. by Fernando Gómez Redondo (San Millán de la Cogolla: Cilengua), pp. $649-667$

CORDE: Corpus Diacrónico del Español (Madrid: Real Academia Española) < $\underline{\text { http:// corpus.rae. }}$ es/cordenet.html> [accesed 2O-O2-2O2I]

Corominas, Joan (ed.). 1967. Juan Ruiz, Arcipreste de Hita, Libro de Buen Amor (Madrid: Gredos)

De Beni, Matteo. 202I. 'La caracterización lingüística en el Cancionero de Llavia: versiones y textos únicos', Criticón, I4I, pp. IO9-I32 <https://doi.org/IO.4000/criticon.I9I49> [accessed o6-o82O2I]

Devoto, Daniel. 1975. 'Los instrumentos de la Coronación de Nuestra Señora, de Fernán Ruiz, según un nuevo texto', Anuario Musical, 30: 36-47

Diccionario de autoridades. I726-I739 (Madrid: Real Academia Española) < $\underline{\text { https://apps.rae.es/ }}$

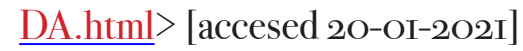

DRAE: Real Academia Española. Diccionario de la lengua española (Madrid: Real Academia

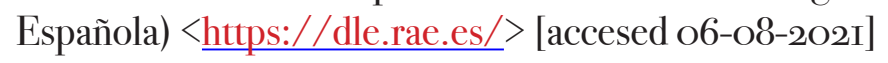

Dutton, Brian. I990-I991. El Cancionero del siglo XV (c. 1360-1520), 7 vols, Biblioteca Española del Siglo XV Maior, I-7 (Salamanca: Universidad de Salamanca)

Gómez Redondo, Fernando. 20I6. 'El arte mayor y el adónico doblado', in Historia de la métrica medieval castellana, ed. by Fernando Gómez Redondo (San Millán de la Cogolla: Cilengua), pp. 489-502

Lázaro Carreter, Fernando. 1972. 'La poética del arte mayor castellano', in Studia in honorem Rafael Lapesa (Madrid: Gredos), I: 343-378

López Casas, María Mercè. 202O. 'Materialidad y estructura de un temprano cancionero colectivo incunable (86*RL)', Revista de Poética Medieval, 34: I3I-I58 <https://doi.org/IO.37536/ RPM.2020.34.0.7839I>

López Casas, María Mercè. 2O2I. 'Los poemas de 86 *RL, criterios de selección y relación con otros incunables poéticos: variación y variantes', Criticón, I4I: I33-I56 <https://doi.org/IO.4000/ criticon.Ig208 $>$ [accesed o6-O8-2O2I]

Martín Abad, Julián. 20I4. 'El día después del Catálogo bibliográfico de la colección de incunables de la Biblioteca Nacional de España', in 'Vir bonus dicendiperitus': Studies in Honor of Charles B. 
Faulhaber, ed. by Antonio Cortijo Ocaña, Ana María Gómez-Bravo and María Morrás (New York: Hispanic Seminary of Medieval Studies), pp. I29-I53

Martínez Pérez, Antonia. 2020. 'Los decires del Cancionero de Llavia: delimitación y estudio del corpus', Revista de Poética Medieval, 34: 25 I-270 < $\underline{\text { https://doi.org/IO.37536/ }}$ RPM.2020.34·0.77683>

Martos, Josep Lluís (ed.). 20I3. Joan Roís de Corella Psalteri, Biblioteca d’Autors Valencians, 59 (València: Institució Alfons el Magnànim)

Martos, Josep Lluís. 20I7. 'Decisiones ecdóticas ante la reescritura de la poesía', in Variación y testimonio único: La reescritura de la poesía, ed. by Josep Lluís Martos (Alacant: Universitat d'Alacant), pp. 9-12

Méndez Bejarano, Mario. I922-I925. Diccionario de escritores, maestros y oradores naturales de Sevilla, 3 vols (Sevilla: Tip. Gironés)

Pedrell, Felipe. I9oI. Emporio científico e histórico de organografía musical antigua española (Barcelona: Juan Gili)

Pérez Priego, Miguel Ángel. 20I4. 'Variantes de imprenta en la poesía del Marqués de Santillana', in La poesía en la imprenta antigua, ed. by Josep Lluís Martos (Alacant: Universitat d'Alacant), pp. I59-I7I

Porras Robles, Faustino. 2008. 'Los instrumentos musicales en la poesía castellana medieval: enumeración y organología', Lemir, I2: II3-г36 〈https://go.uv.es/doSgMQc $>$

Pujol, Emilio (ed.). 1984. Alonso Mudarra, Tres libros de música en cifra para vihuela, Sevilla 1546 (Barcelona: Consejo Superior de Investigaciones Científicas)

Rodríguez-Moñino, Antonio. 1970. Diccionario bibliográfico de pliegos sueltos poéticos (siglo XVI) (Madrid: Castalia)

Rodríguez-Moñino, Antonio et al. 1997. Nuevo diccionario bibliográfico de pliegos sueltos poéticos (siglo XVI) (Madrid: Editora Regional de Extremadura) 